\title{
DETERMINATION OF PHTHALATES IN PLUM SPIRIT AND THEIR OCCURRENCE DURING PLUM SPIRIT PRODUCTION
}

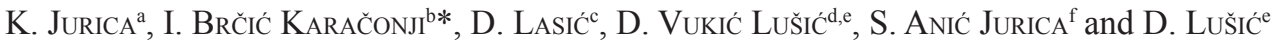

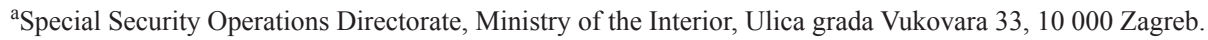 \\ Croatia \\ ${ }^{\mathrm{b}}$ Analytical Toxicology and Mineral Metabolism Unit, Institute for Medical Research and Occupational Health, \\ Ksaverska cesta 2, 10000 Zagreb. Croatia \\ ${ }^{c}$ Department of Environmental Protection and Health Ecology, Dr. Andrija Štampar Institute of Public Health, \\ Mirogojska St. 16, 10000 Zagreb. Croatia \\ ${ }^{\mathrm{d}}$ Department of Ecology, Teaching Institute of Public Health, Krešimirova 52a, 51000 Rijeka. Croatia \\ ${ }^{\mathrm{e}}$ Department for Environmental Health, Faculty of Medicine, University of Rijeka, Braće Branchetta 20. 51000 \\ Rijeka. Croatia \\ ${ }^{\mathrm{f}}$ Department of Gynecology and Obstetrics, University Hospital Centre Zagreb, Petrova 13, 10000 Zagreb. \\ Croatia
}

(Received: 26 April 2015; accepted: 12 May 2015)

Phthalates are ubiquitous environmental contaminants that, due to their lipophilicity, migrate more readily into beverages with higher ethanol content. The aim of this work was to study the occurrence of phthalates in samples during the plum spirit production and in the final product, plum spirit manufactured by registered producers from five European countries, using gas chromatography-mass spectrometry (GC-MS). A decreasing trend of mean values was observed for diethyl phthalate (DEP), di-iso-butyl phthalate (DiBP), and di- $n$-butyl phthalate (DBP) as the distillation process went on. Levels of benzyl-butyl phthalate (BBP) and di-(2-ethylhexyl) phthalate (DEHP) increased in the distillation phase compared to concentrations in the preceding phases. In commercial plum spirits, DEHP and DiBP were detected in the highest concentrations. Results also indicated that a moderate daily consumption of plum spirit does not pose a health risk regarding the Tolerable Daily Intake of BBP, DEHP, and DBP. Keywords: phthalates, plum spirit, gas chromatography-mass spectrometry, distillation

Exposure to phthalates can occur via ingestion of food/beverage contaminated with plasticizers (HEudorf et al., 2007). Due to their toxicity, safety margins of exposure were set for the most relevant phthalates in food and beverages. World Health Organization (WHO) has set the maximum allowable level of di-(2-ethylhexyl) phthalate (DEHP) in drinking water at $8 \mu \mathrm{g} \mathrm{l}^{-1}(\mathrm{WHO}, 2005)$. Slovakian legislation defines the maximum allowable amount of phthalates as the sum of DEHP and di- $n$-butyl phthalate (DBP) $\left(2 \mathrm{mg} \mathrm{kg}^{-1}\right)$ in fruit, leafy vegetables, flour, and alcoholic beverages (Ministerstvo PôdohospodáRstva SlovenskeJ Republiky a Ministerstvo Zdravotníctva Slovenskej Republiky, 2004). European Food Safety Authority (EFSA) established the Tolerable Daily Intake (TDI) values for benzylbutyl phthalate (BBP), DBP, and DEHP as 500, 10, and $50 \mu \mathrm{g} \mathrm{kg}^{-1}$ body weight (bw), respectively (EFSA, 2005a, b, c).

Spirits, which includes all distilled beverages, constitute $50.1 \%$ of all alcoholic beverages consumed worldwide, $15 \%$ in Croatia (WHO, 2014). Due to the widespread presence of phthalates, the production of plum spirit carry a risk of phthalate contamination during the

\footnotetext{
* To whom correspondence should be addressed.

Phone: +385-1-4682 500; fax: +385-1-4673 303; e-mail: ibrcic@imi.hr
} 
harvesting (plastic pipes and collecting bags), manufacturing (in tubing and pumps that connect different production phases), and packaging process (JURICA et al., 2013; CHATONNET et al., 2014). Thus, exposure to phthalates from spirits in general population could not be neglected and should be monitored. Plum spirit is a distilled alcoholic beverage traditionally made in countries of Central and Eastern Europe. In Croatia, in 2012, 1650001 (0.04 1 per capita (adults 15+ years)) of plum spirit was sold legally on the domestic market and approximately $72 \%$ (415 000 1) of the legally produced plum spirit is exported (CADP, 2013).

The main objectives of this study were to determine the concentrations of different phthalates (dimethyl phthalate (DMP), diethyl phthalate (DEP), DBP, di-iso-butyl phthalate (DiBP), BBP, DEHP, and di- $n$-octyl phthalate (DOP)) during the five stages of Croatian plum spirit manufacturing process and concentrations of phthalates in the final product - plum spirit manufactured by registered producers from Croatia, Slovenia, Austria, Serbia, and Bosnia and Herzegovina; and to assess the risk of phthalate intake for the population consuming legally produced plum spirit. To the best of our knowledge, this is the first paper to report the DMP, DEP, DBP, DiBP, BBP, DEHP, and DOP levels in plum spirits of registered producers from multiple countries.

\section{Materials and methods}

\subsection{Chemicals}

Standards of DMP, DEP, DBP, DiBP, BBP, DEHP, and DOP, all of $\geq 98 \%$ purity were purchased from Supelco (Bellefonte, USA). Dichloromethane and hexane (HPLC grade) were obtained from Merck (Darmstadt, Germany) and anhydrous sodium sulphate (analytical grade) from Kemika (Zagreb, Croatia).

\subsection{Sampling}

Random samples of plum mash and plum distillate $(\mathrm{N}=67)$ were taken at a plum distillate production facility of a registered Croatian plum spirit producer during each of the five stages of the technological process: admission $(\mathrm{N}=26)$, pureeing $(\mathrm{N}=12)$, fermentation $(\mathrm{N}=6)$, transfer tank $(\mathrm{N}=8)$, and distillation $(\mathrm{N}=15)$. The samples were stored in glass and plastic containers and frozen at $-18{ }^{\circ} \mathrm{C}$ until analysis. The results were expressed as $\mu \mathrm{g}$ of phthalate per $\mathrm{kg}$ of plums. The sampling was carried out on a single batch of plums imported from two suppliers from surrounding countries and taken into the process of making the spirit. The sampling was done according to the modified standard protocol described by the Commission Regulation (EC) No 333/2007 (EC, 2007).

The commercially available plum spirits manufactured by eight different producers were purchased at several various supermarkets. Twenty $(\mathrm{N}=20)$ samples were taken altogether; two from each of the seven brands (three Croatian, one Austrian, one brand from Bosnia and Herzegovina, one Serbian, and one Slovenian; one sample per batch) and six samples from different batches of plum spirit produced by one registered Croatian producer using the process described in this study. These plum spirits, packed in labelled glass bottles with twist-off caps with documentary stamps, were analysed immediately upon purchase. The results of analysis were expressed as $\mu \mathrm{g}$ of phthalate per 1 of spirit. 


\subsection{GC-MS analysis}

A $2 \mathrm{ml}$ of plum mash, plum distillates, or plum spirit sample was extracted at $\mathrm{pH} 4-5$ with 3 $\mathrm{ml}$ of dichloromethane in a 10-ml glass tube. After 10 min of mixing using Ultra-Turrax (IKA-Werke GmbH \& Co. KG, Germany) at 2500 r.p.m., the mixture was left to settle until the layers separated. The water layer was discarded and $2 \mathrm{~g}$ of anhydrous sodium sulphate was added to the organic extract to remove the residual water. An aliquot of $1 \mu l$ of extract was injected into the GC-MS system. Blank samples were prepared in the same way as samples, using $2 \mathrm{ml}$ of deionised water instead of spirit. The blank concentration of each phthalate was subtracted from the concentration found in the sample.

Analysis was performed on a Thermo Scientific gas chromatograph-mass spectrometer Trace 1300-ITQ 700 (Milan, Italy). One $\mu 1$ of extract was injected in splitless mode at $280^{\circ} \mathrm{C}$. Analytes were separated onto a DB- 5 capillary column $(30 \mathrm{~m} \times 0.25 \mathrm{~mm}, 0.25 \mu \mathrm{m}$ film

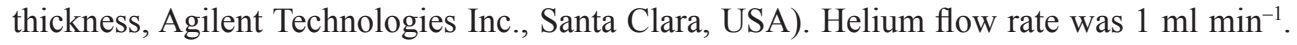
The $\mathrm{GC}$ oven temperature was set at $40{ }^{\circ} \mathrm{C}$ for $5 \mathrm{~min}$, raised to $280{ }^{\circ} \mathrm{C}$ at $10^{\circ} \mathrm{C} \mathrm{min}^{-1}$, and held for $21 \mathrm{~min}$ at $280^{\circ} \mathrm{C}$. The temperature of the transfer line and the ion source was $250^{\circ} \mathrm{C}$. The MS was operated in electron ionization mode $(70 \mathrm{eV})$. Selected ion monitoring was used for quantification ( $/ \mathrm{z} 163$ for DMP and $\mathrm{m} / \mathrm{z} 149$ for DEP, DBP, DiBP, BBP, DEHP, and DOP). Limit of detection (LOD) and limit of quantification (LOQ) ranged from $1.17 \mu \mathrm{g} \mathrm{l}^{-1}$ (DMP) to $4.30 \mu \mathrm{g} \mathrm{l}^{-1}$ (DOP) and from $3.90 \mu \mathrm{g} \mathrm{l}^{-1}$ (DMP) to $14.32 \mu \mathrm{g} \mathrm{l^{-1 }}$ (DOP). Analytical recoveries ranged from $92.3 \%$ (DMP) to $98.6 \%$ (DEHP).

\subsection{Statistical analysis}

Statistical analyses were performed using Statistica9 for Windows (StatSoft, USA). Concentrations of the same phthalates in different sampling containers were compared by Mann-Whitney test. A $\mathrm{P}<0.05$ was considered statistically significant.

\section{Results and discussion}

Seven different phthalates were monitored in samples $(\mathrm{N}=67)$ taken from five different phases in the plum spirit production process. DMP and DOP were below the LOD. DEP, DiBP, and DBP were detected in $32.8 \%$ while DEHP and BBP were detected in $26.9 \%$ and $7.5 \%$ of the samples, respectively (Table 1). A decreasing trend of mean values was observed for low-molecular weight and more volatile DEP, DBP, and DiBP as the process continued. Phthalates were present in the earliest phase, even before the beginning of the production process, presumably due to the plastic bags used during the plum picking and storing. At the admission and pureeing phase, DEHP was detected to a lesser extent (less than $20 \%$ of the samples). In the final phase of plum spirit production (distillation), mean concentrations of BBP and DEHP increased by 68.8 and $52.9 \%$, respectively, compared to their concentration in the penultimate phase (transfer tank). The probable reason is that the plum distillate, as a more acidic medium, might have drawn out BBP and DEHP from the plastic and rubber components of the pumps or other equipment used in production. Such a stimulating effect from an acidic medium on phthalate migration from plastic has been described by BoŠNIR and co-workers (2007). 


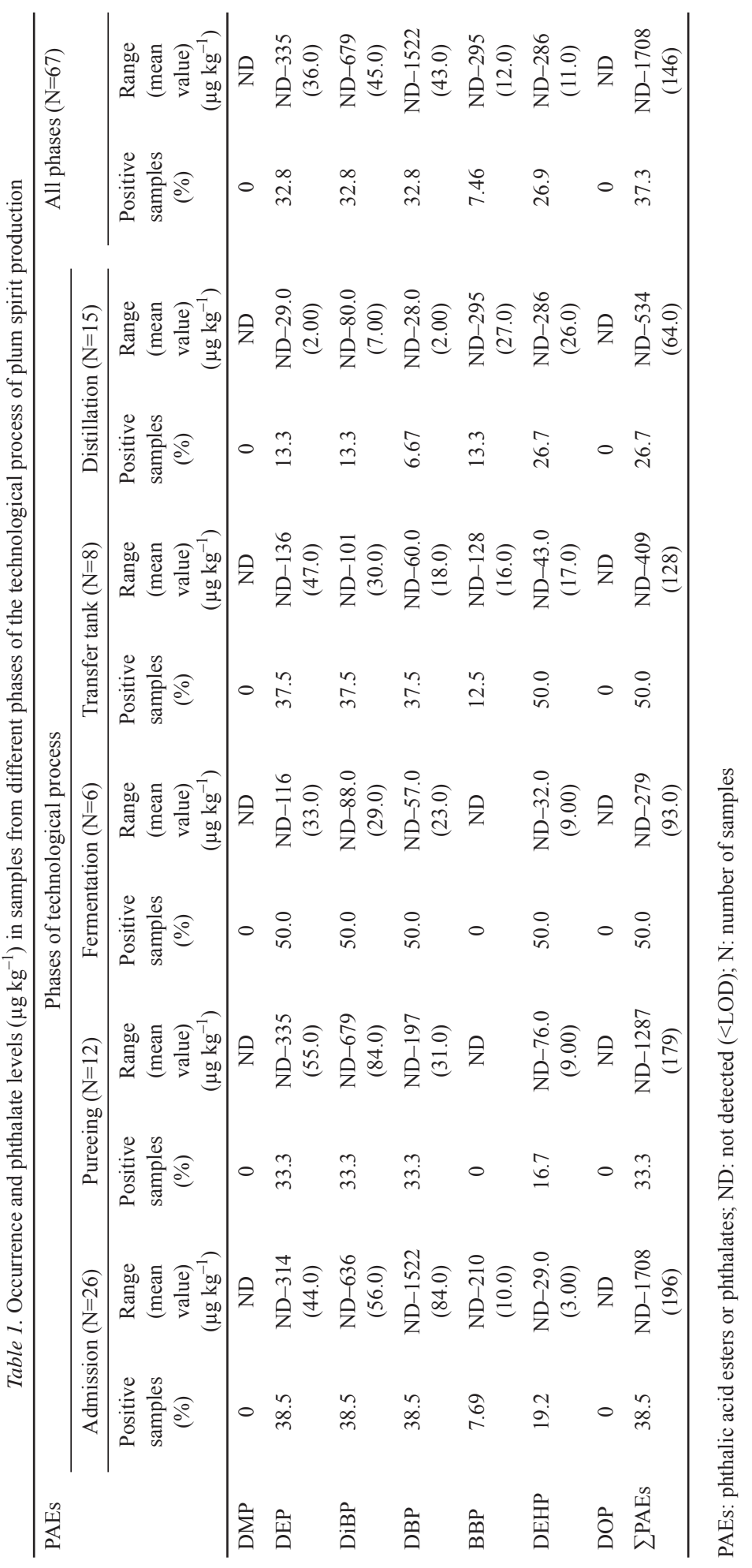


No significant difference in phthalate concentrations was observed for type of container, although glass containers displayed slightly lower concentrations. This study showed that the packaging materials (glass vs. plastic) had no evident influence, which is in accordance with studies by CARRILlO and co-workers (2008) and DEL CARLO and co-workers (2008), which tested the impact of packaging material on phthalate content in wine samples.

Phthalate concentrations determined in 20 glass bottled plum spirit samples from five different countries of Central and Eastern Europe are presented in Table 2. DMP and DOP were below the LOD in all of the analysed samples. The highest concentrations were found for DBP (mean 414.5 $\mu \mathrm{g}^{-1}$ ) and DEHP (mean $423.8 \mu \mathrm{g} \mathrm{l}^{-1}$ ), which are the two most commonly identified phthalates in spirits (LeiBowitz et al., 1995, Chatonnet et al., 2014). The higher levels of DBP, BBP, and DEHP might have been caused by either contamination during production or the process of bottling or phthalate migration from the stoppers during storage. CHATONNET and co-workers (2014) reported similar results for DBP and DEHP concentrations in French grape spirit, while BBP levels were higher in our study. DBP (22-204 $\left.\mu \mathrm{g} \mathrm{l}^{-1}\right)$ and DEHP (128-492 $\mathrm{g}^{-1}$ ) concentrations in vodka samples determined by LEIBOwITZ and coworkers (1995) were lower than concentrations measured in our study. Within this Alcohol Measures for Public Health Research Alliance (AMPHORA) project, which assessed the quality of illegally produced alcohol in a European-wide study, different phthalates (DMP, DEP, diallyl phthalate (DAP), DiBP, DBP, BBP, DEHP, diheptyl phthalate (DHP), and DOP) were measured, but not detected, in six samples of Croatian homemade spirits (pear, plum, and marc) (LACHENMEIER et al., 2011). The probable reason why phthalates were not detected in these spirits was low sensitivity of the analytical method used. The same phthalates were measured in 257 samples of alcoholic beverages in the study by LEITZ and co-workers (2009), in which only two samples contained DEP (used as denaturing agent for ethyl alcohol) in concentrations of $608 \mathrm{mg} \mathrm{l}^{-1}$ and $210 \mathrm{mg} \mathrm{l}^{-1}$, while other phthalates were not detected. Phthalate concentrations in different wines are lower than those measured in spirits. CARRILLO and co-workers (2008) showed that DBP was the main phthalate found in wine $(\mathrm{N}=10)$, followed by DEHP and DEP, with total phthalate concentrations between 2.7 and $15 \mu \mathrm{g} \mathrm{l}^{-1}$. Cinelli and co-workers (2013) reported DEHP and DBP concentrations of up to 26.6 and $312.4 \mu \mathrm{g} \mathrm{l}^{-1}$, respectively, in commercial wines $(\mathrm{N}=11)$. In white and red wines $(\mathrm{N}=36)$ from Italy, DiBP, DBP, BBP, and DEHP were found at the average level of $45-115 \mu \mathrm{g} \mathrm{l}^{-1}$ (DEL CARLO et al., 2008). Lower phthalate concentration in wines compared to spirits might be explained by the lower ethanol content in wine. Due to their lipophilicity, phthalates migrate more readily into beverages with higher ethanol content, like spirits (CHATONNET et al., 2014).

Table 2. Concentration of phthalates $\left(\mu \mathrm{g} \mathrm{l^{-1 }}\right)$ in eight different brands of plum spirit $(\mathrm{N}=20)$

\begin{tabular}{lcc}
\hline Phthalates & Mean \pm SD & Median (Range) \\
\hline DMP & ND & ND \\
DEP & $16.7 \pm 15.3$ & $7.8(4.2-50.0)$ \\
DiBP & $38.3 \pm 13.9$ & $38.8(20.1-65.7)$ \\
DBP & $414.5 \pm 355.9$ & $405.6(25.2-822.0)$ \\
BBP & $78.9 \pm 39.7$ & $79.0(10.5-122.0)$ \\
DEHP & $423.8 \pm 524.6$ & $282.0(16.0-1638.0)$ \\
DOP & ND & ND \\
\hline
\end{tabular}

ND: not detected (<LOD); N: number of samples 
Phthalate levels in alcoholic beverages have not yet been regulated. The EFSA established TDI values only for DBP, BBP, and DEHP (EFSA, 2005a, b, c) and these values were used in this study to estimate the drinking volume of plum spirit containing DBP, BBP, and DBP that a $60-\mathrm{kg}$ person could drink every day without apparent harmful effects potentially attributed to the intake of phthalates (Table 3). Assuming the worst-case scenario, the plum spirit sample with the highest DBP, BBP, and DEHP concentration was used for exposure calculation. The estimation showed that a daily intake of 0.731 of plum spirit could be critical to human health regarding the exposure to DBP. Having this in mind, a daily consumption of one standard drink $(0.03 \mathrm{l})$ does not pose a health risk. It should be pointed out that in cases of excessive drinking, the main health risk would arise from the high intake of ethanol. Our results also showed that the BBP, DEHP, and DBP intake for a $60-\mathrm{kg}$ person drinking one 0.03 -1 glass of legally produced plum spirit, accounts for $0.01,1.6$, and $4.1 \%$ of the TDI for these phthalates, respectively. The main concern, however, is that, apart from legally produced plum spirit, people are also exposed to phthalates from homemade alcoholic beverages, which account for approx. 30\% of all alcohol consumed (REHм et al., 2014).

Table 3. Exposure evaluation of plum spirit with regard to DBP, BBP, and DEHP concentration

\begin{tabular}{lccc}
\hline Phthalates & $\begin{array}{c}\text { Concentration in plum spirit } \\
\left(\mu \mathrm{g} \mathrm{l}^{-1}\right)\end{array}$ & $\begin{array}{c}\text { TDI } \\
\left(\mu \mathrm{gg}^{-1} \mathrm{bw} / \text { day }\right)\end{array}$ & $\begin{array}{c}\text { Drinking volume for a 60-kg } \\
\text { person to exceed TDI } \\
\left(1 \text { day }^{-1}\right)\end{array}$ \\
\hline DBP & 822 & 10.0 & 0.73 \\
BBP & 122 & 500 & 246 \\
DEHP & 1638 & 50.0 & 1.83 \\
\hline
\end{tabular}

TDI: Tolerable Daily Intake; ${ }^{\text {a }}$ Drinking volume $(1)=\left[\right.$ TDI $\left(\mu \mathrm{g} \mathrm{kg}^{-1}\right.$ bw/day $\left.) \times 60 \mathrm{~kg}\right] / \mathrm{mass}$ concentration $\left(\mu \mathrm{g}{ }^{-1}\right)$

It should be noted that the general population is exposed to phthalates from different sources (food, drink, dermal/inhalatory consumer products), so estimated exposure from spirits adds up the total intake amount. Also, human diet, as seen here for spirits, is contaminated with a mixture of different phthalates, all bearing it's individual health risks.

\section{Conclusions}

This study quantified phthalates from the five stages of plum spirit production, as well as from marketed plum spirits from the countries in the region. Contamination of plum mash, distillate, and spirit with DEP, DiBP, and DBP may have arisen from storing plums in plastic bags during harvesting rather than from the technological process itself. The probable reason for the occurrence of BBP and DEHP in plum distillate was the drawing out of the phthalates from the plastic and rubber equipment in the technological process due to the more acidic nature of the distillate. Detection of phthalates in different natural spirits produced in controlled conditions suggested that monitoring of phthalates during production process is necessary, although phthalates determined in this study may not have significance when plum spirit is consumed in a moderate manner. Considering the widespread occurrence of phthalates in the environment and their detection in different alcoholic beverages, the monitoring of 
phthalates should be the part of internal quality management and product safety control systems.

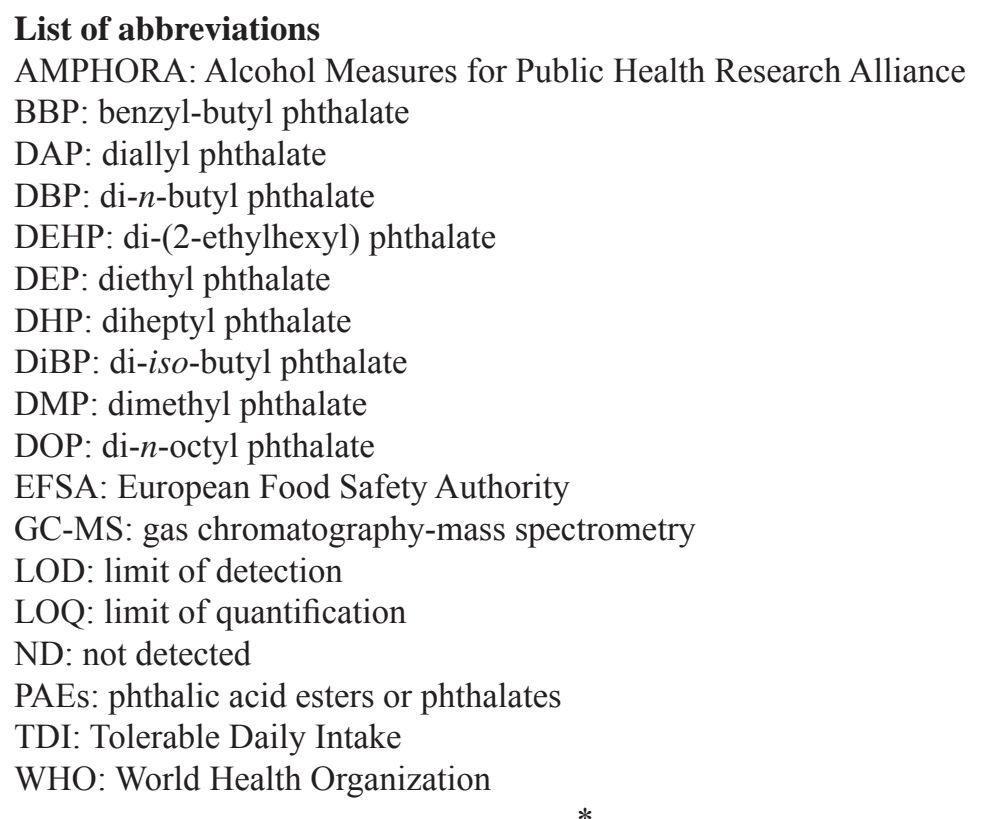

This work has been supported by the Croatian Science Foundation under the project 8366

\section{References}

Bošnir, J., Puntarić, D., Galić, A., Škes, I., Dijanić, T., Klarić, M., Grgić, M., Čurković, M. \& Šmit, Z. (2007): Migration of phthalates from plastic containers into soft drinks and mineral water. Food Technol. Biotech., 45, 91-95.

Carrillo, J.D., Martínez, M.P. \& Tena, M.T. (2008): Determination of phthalates in wine by headspace solid-phase microextraction followed by gas chromatography-mass spectrometry. Use of deuterated phthalates as internal standards. J. Chromatogr. A., 1181, 125-130.

Chatonnet, P., Boutou, S. \& Plana, A. (2014): Contamination of wines and spirits by phthalates: types of contaminants present, contamination sources and means of prevention. Food Addit. Contam. Part A Chem. Anal. Control Expo. Risk Assess., 31, 1605-1615.

Cinelli, G., Avino, P., Notardonato, I., Centola, A. \& Russo, M.V. (2013): Rapid analysis of six phthalate esters in wine by ultrasound-vortex-assisted dispersive liquid-liquid micro-extraction coupled with gas chromatographyflame ionization detector or gas chromatography-ion trap mass spectrometry. Anal. Chim. Acta., 769, 72-78.

CADP (2013): Report on plum spirit realization in 2012. Croatian Association of Drink Producers.

Del Carlo, M., Pepe, A., Sacchetti, G., Compagnone, D., Mastrocola, D. \& Cichelli, A. (2008): Determination of phthalate esters in wine using solid-phase extraction and gas chromatography-mass spectrometry. Food Chem., 111, 771-777.

EC (2007): Commission Regulation (EC) No 333/2007 of 28 March 2007 laying down the methods of sampling and analysis for the official control of the levels of lead, cadmium, mercury, inorganic tin, 3-MCPD and benzo(a) pyrene in foodstuffs (Text with EEA relevance). European Commission. OJEU, L88, 29-38.

EFSA (2005a): Opinion of the scientific panel on food additives, flavourings, processing aids and material in contact with food (AFC) related to di-butylphthalate (DBP) for use in food contact materials. Question $N^{\circ}$ EFSA-Q-2003-192. European Food Safety Authority. EFSA Journal, 242, 1-17. 
EFSA (2005b): Opinion of the scientific panel on food additives, flavourings, processing aids and materials in contact with food (AFC) related to bis(2-ethylhexyl)phthalate (DEHP) for use in food contact materials. Question $N^{\circ}$ EFSA-Q-2003-191. European Food Safety Authority, EFSA Journal, 243, 1-20.

EFSA (2005c): Opinion of the scientific panel on food additives, flavourings, processing aids and materials in contact with food (AFC) related to butylbenzylphthalate (BBP) for use in food contact materials Question $N^{\circ}$ EFSA-Q-2003-190. European Food Safety Authority. EFSA Journal, 241, 1-14.

Heudorf, U., Mersch-Sundermann, V. \& Angerer, J. (2007): Phthalates: Toxicology and exposure. Int. J. Hyg. Envir. Heal., 210, 623-634.

Jurica, K., Uršulin-Trstenjak, N., Vukić Lušić, D., Lušić, D. \& Šmit, Z. (2013): Izloženost ftalatima i njihova pojavnost u alkoholnim pićima (Exposure to phtalates and their presence in alcoholic beverages). Arh. Hig. Rada Toksikol., 64, 317-325.

Lachenmeier, D.W., Leitz, J., Schoeberl, K., Kuballa, T., Straub, I. \& Rehm, J. (2011): Quality of illegally and informally produced alcohol in Europe: Results from the AMPHORA project. Adicciones, 23, 133-140.

Leibowitz, J.N., Sarmiento, R., Sugar, S.M. \& Ethridge, M.W. (1995): Determination of six common phthalate plasticizers in grain neutral spirits and vodka. J. AOAC Int., 78, 730-735.

Leitz, J., Kuballa, T., Rehm, J. \& Lachenmeier, D.W. (2009): Chemical analysis and risk assessment of diethyl phthalate in alcoholic beverages with special regard to unrecorded alcohol. PloS ONE, 4, e8127.

Ministerstvo Pôdohospodárstva Slovenskej Republiky A Ministerstvo Zdravotníctva Slovenskej Republiky (2004): Výnos Ministerstva pôdohospodárstva Slovenskej republiky a Ministerstva zdravotníctva Slovenskej republiky z 15. marca 2004 č. 608/3/2004-100, ktorým sa vydáva hlava Potravinového kódexu Slovenskej republiky upravujúca kontaminanty v potravinách (Decree No. 608/3/2004-100 of the Ministry of Agriculture and Ministry of Health of the Slovak Republic of 15 March 2004 laying down the Food codex chapter of the Slovak Republic on food contaminants.) Vestník Ministerstva pôdohospodárstva Slovenskej republiky, 36, 113.

Rehm, J., Kailasapillai, S., Larsen, E., Rehm, M.X., Samokhvalov, A.V., Shield, K.D., Roerecke, M. \& Lachenmeier, D.W. (2014): A systematic review of the epidemiology of unrecorded alcohol consumption and the chemical composition of unrecorded alcohol. Addiction, 109, 880-893.

WHO (2005): Guidelines for drinking-water quality. Chapter 12: Chemical aspects, $3^{\text {rd }}$ edn., World Health Organization, Geneva. pp. 296-460.

WHO (2014): Global status report on alcohol and health. World Health Organization, Geneva, 392 pages. 